$(\mathrm{S}, \mathrm{n}=30)$. The MI model was set up in $\mathrm{SD}$ rats by permanent ligation of the left anterior descending coronary artery. In $S$ group suture was through the left anterior descending coronary artery without ligation. Before and after MI, in NL group/S group and T group normal saline and Trimetazidine $(0.3 \mathrm{mg} / \mathrm{kg})$ were separately given by gavage. The changes of serum cTnI were observed at 8, 24, $48 \mathrm{~h}$ after MI. The changes of serum cTnI in S group was only observed at 24th hour after operations. In 1 week, 2 weeks and 4 weeks after treatment, the areas of myocardial infarction were analysed, and isovolumic systolic left ventricular maximum rate of pressure rise $\left(+\mathrm{dp} / \mathrm{dt}_{\max }\right)$ and isovolumic diastolic left ventricular maximum rate of pressure drop $\left(-\mathrm{dp} / \mathrm{dt}_{\mathrm{min}}\right)$ were measured to evaluate the myocardial protection effects of STV-1Na. The groups were compared with one-way analysis of variance (ANOVA) test. A value of $p 0.05$ between NL group and T group. But the serum cTnI level at $24 \mathrm{~h}$ after MI decreased in $\mathrm{T}$ group $(22.7 \pm 5.3 \mathrm{ng} / \mathrm{ml}, \mathrm{p}<0.05)$ compared with NL group $(42.3 \pm 5.4 \mathrm{ng} / \mathrm{ml})$. The serum cTnI level at $24 \mathrm{~h}$ in NL group and T group was significantly increased compared with $\mathrm{S}$ group $(1.59 \pm 1.42 \mathrm{ng} / \mathrm{ml}) \quad(\mathrm{p}<0.01)$. Trimetazidine $(0.248 \pm 0.021, \quad p<0.01)$ decreased significantly the myocardial infarction area compared with NL group $(0.362 \pm 0.027)$. The infarction areas in $\mathrm{NL}$ group $(0.362 \pm 0.027)$ and $\mathrm{T}$ group $(0.248 \pm 0.021)$ increased significantly compared with $S$ group $(0.072 \pm 0.1445)$ $(p<0.01)$. In 1 week after MI, the $+d p / d t_{\max }$ in $T$ group $(7535 \pm 265)$ was not significantly different $(p>0.05)$ compared with NL group (6702 \pm 329$)$, and the $-\mathrm{dp} / \mathrm{dt}_{\min }$ in $\mathrm{T}$ group $(-5511 \pm 400)$ was no significant difference $(p>0.05)$ compared with $\mathrm{NL}$ group $(-5400 \pm 339)$. In 2 weeks after $\mathrm{MI}$, the $+\mathrm{dp} / \mathrm{dt}_{\max }$ in $\mathrm{T}$ group $(8101 \pm 313)$ increased significantly compared with NL group $(5868 \pm 412)(p<0.01)$, and the $-d p / d t_{m i n}$ in $T$ group $(-6514 \pm 493)$ decreased significantly compared with NL group $(-4750 \pm 463)(p<0.05)$. In 4 weeks after MI, in T group $(7629 \pm 374)$ the $+\mathrm{dp} / \mathrm{dt}$ max increased significantly compared with NL group $(5876 \pm 200)(\mathrm{p}<0.01$,$) , and the -\mathrm{dp} / \mathrm{dt}_{\min }$ in T group $(-5883 \pm 436)$ decreased significantly compared with NL group $(-4546 \pm 279)$ $(p<0.05)$. The $-d p / d t$ max in T group and NL group were significantly decreased $(p<0.05)$ compared with $S$ group in 1 week, 2 weeks and 4 weeks after the operation. The $+\mathrm{dp} / \mathrm{dt}_{\min }$ in $\mathrm{T}$ group and NL group were increased $(p<0.05)$ compared to $S$ group in 1 week, 2 weeks and 4 weeks after the operation.

Conclusions Trimetazidine has myocardial protection effects on myocardial infarction and improves myocardial systolic and diastolic function in SD rats with acute myocardial infarction.

\section{e0185 THE EFFECT OF CLASSIC MAPKERK5 PATHWAY ON HYPERTHERMIA INDUCED VENTRICULAR CARDIOMYOCYTES DAMAGE}

doi:10.1136/hrt.2010.208967.185

Xiao Huang, Xiao-Shu Cheng, Xiao-Ming Bao, Ju-Xiang Li, Kui Hong. Department of Cardiology, Second Hospital of Nanchang University, Nanchang, China

Objective In China, the occurrence rule, mechanisms and prevention measures of diseases under extreme weather are few reported and which (del) only focused (focus) on pathophysiological manifestation rather than molecular mechanism level. So (del) (Thus,) further study in this work will be carried out from molecular cytological level. This study explored (del) the effect of hyperthermia on ventricular cardiomyocytes and the participative roles of classic MAPK - ERK5 pathways on hyperthermia induced cardiomyocytes damage.

Methods Neonatal rat ventricular cardiac myocytes (NRVM) were isolated from the hearts of 1- to 3-day-old Sprague Dawley rats. NRVM were exposed to a hyperthermia $\left(42^{\circ} \mathrm{C}, 60 \mathrm{~min}\right)$ environment. The degree of cell damage was observed at $0,4,8,12,16$, and $24 \mathrm{~h}$ after recovery. The effects of hyperthermia on myocardial cells were probed by evaluating lactate dehydrogenase (LDH) release, cells beating rate and rhythm and viability (assessed by MTS assay). Apoptosis was detected using an annexin V-FITC/propidium iodide (PI) staining binding assay. Using western blot semi-quantitating Bim and extracellular signal-related kinase (ERK5) / phosphorylated extracellular signal-related kinase (p-ERK)(??). Using PD98059 as an inhibitor of MAPK pathways, semi-quantitating Bim by western blot(??).

Results 1 . The beating rate of myocardial cells was slightly decreased immediately after temperature recovery, (del)(and) gradually decreased with time prolonged, and the (del)(.) Cell viability was (del) decreased $(p<0.05)$; (and) the activity of lactate dehydrogenase was (del) increased $(p<0.05)$. 2. Based on western blot analysis, the elevation of Bim protein expression occurred at recovery time $(8 \mathrm{~h})$ and $(\mathrm{del})($,$) peaked at 12 \mathrm{~h}($,$) then went down$ slowly at $24 \mathrm{~h}$ after hyperthermia $(\mathrm{p}<0.05)$; ERK5 pathway responding to hyperthermia treatment $(p<0.05)$. 3. Levels of Bim slightly decreased at (in) PD98059 group compared with hyperthermia group $(p<0.05)$.

Conclusions Hyperthermia induces myocardial cells damage with apoptosis as main type. ERK5 participated the injure process of hyperthermia and Bim played its role via a MAPK-ERK5 pathway.

\section{e0186 STUDY ON THE MECHANISM OF INHIBITORY EFFECT OF CTLA-4IG FUSION PROTEIN ON ATHEROSCLEROSIS IN APOE DEFICIENT MICE}

doi:10.1136/hrt.2010.208967.186

Li Yujie, Zheng Dongdan, Chen Jie, Li Xin, Xiong Yan, Liao Xiaoxing. The First Affiliated Hospital Sun Yatsen University, Guangzhou, China

Objective To investigate the mechanism of inhibitory effect of CTLA-4Ig fusion protein on atherosclerosis in mice with an apolipoprotein-E gene defect fed on cholesterol diet.

Methods 30 male 10-week-old apoE(-/-) mice were fed on cholesterol diet and divided into CTLA-4Ig treatment group, IgG1 group and PBS group at random, 10 in each. The three groups were given intraperitoneal injection of CTLA-4Ig (10 $\mu \mathrm{g}$ per time), Rat-IgG1 (10 $\mu \mathrm{g}$ per time), (and) PBS (100 $\mu \mathrm{l}$ per time) respectively, twice a week, for 12 weeks. Followed by a 12 -week treatment, the whole aorta from the root to crotch of iliac artery was separated after anaesthesia with the intraperitoneal injection of $1 \%$ pentobarbital and the whole (total) blood was taken to obtain serum. Subsequently, the area ratio of plaque and lumen, the thickness ratio of endangium and tunica media, the lipid-soaking extent intra-plaque and the content of collagen fibrils and smooth muscle cells intraplaque were analysed by image-processing soft. The serum concentration of total cholesterol, CRP, sICAM-1, IFN- $\gamma$, IL-10, and TGF- $\beta 1$ were measured.

Results There were typical atherosclerotic plaque in apoE(-/-) mice fed on cholesterol diet after 12 weeks and it was light in the CTLA4Ig group. There were statistical value of difference in the area ratio of plaque and lumen, the thickness ratio of endangium and tunica media, the lipid-soaking extent intra-plaque, and the content of collagen fibrils in three groups $(\mathrm{p}$ all $<0.05)$. It was found that the area ratio of plaque and lumen, the thickness ratio of endangium and tunica media, and the lipid-soaking extent intra-plaque were significant lower and the content of collagen fibrils was higher in the CTLA-4Ig group than those in the IgG1 group and PBS group ( $p$ all $<0.05$ ), but there was no significant difference in those between the IgG1 group and PBS group ( $p$ all $>0.05$ ). There were no significant difference in content of smooth muscle cells in three groups $(p>0.05)$. There were no significant difference in serum concentration of total cholesterol in three groups $(p>0.05)$. There were statistical value of difference in the serum concentration of CRP, 